\title{
The Effect of Probiotics on Reducing Hospitalization Duration in Infants With Hyperbilirubinemia
}

\author{
Mohammad Torkaman, ${ }^{1}$ Fatemeh Mottaghizadeh, ${ }^{2}$ Mohammad Hossein Khosravi, ${ }^{2,}$ Bita Najafian, \\ Susan Amirsalari, ${ }^{3}$ and Shahla Afsharpaiman ${ }^{4}$ \\ ${ }^{1}$ Department of Pediatrics, Baqiyatallah University of Medical Sciences, Tehran, IR Iran \\ ${ }^{2}$ Students' Research Committee, Baqiyatallah University of Medical Sciences, Tehran, IR Iran \\ ${ }^{3}$ New Hearing Technologies Research Center, Baqiyatallah University of Medical Sciences, Tehran, IR Iran \\ ${ }^{4}$ Health Research Center, Baqiyatallah University of Medical Sciences, Tehran, IR Iran \\ "Corresponding author: Mohammad Hossein Khosravi, Students' Research Committee, Baqiyatallah University of Medical Sciences, Tehran, IR Iran. Fax: +98-2188620826, \\ E-mail: dr.mhkhosravi@gmail.com
}

Received 2015 December 20; Revised 2016 July 09; Accepted 2016 August 18

\begin{abstract}
Background: Approximately $60 \%$ of term and $80 \%$ of premature infants are hospitalized for hyperbilirubinemia in the first week of life. Hyperbilirubinemia is the most common cause of infant hospitalization and readmission. Due to the high frequency of hyperbilirubinemia in infants and the high costs of treatment, it is necessary to find a way to decrease hospitalization duration.

Objectives: The aim of this study is to assess the adjunctive effect of probiotics on decreasing hospitalization time for infants with hyperbilirubinemia.

Methods: In this randomized, controlled clinical trial, 92 term infants with hyperbilirubinemia who met the inclusion criteria were randomly assigned to either the probiotic or control group. Patients in both groups underwent common phototherapy. Once a day, those in the probiotic group were also given half of a capsule of Prokid probiotic, while those in the control group received half of a placebo capsule. The duration of phototherapy and hospitalization, the blood groups of mothers and infants, and each patient's bilirubin levels before and after phototherapy, direct Coombs test results, and levels of hemoglobin, G6PD, and reticulocytes were recorded.

Results: Data from 92 patients with a mean age of $5.25 \pm 2.35$ days underwent analysis. The control group had 47 (51.1\%) patients with a mean age of $5.19 \pm 2.51$ days and the probiotic group had $45(48.9 \%)$ patients with a mean age of $5.31 \pm 2.19$ days $(\mathrm{P}=0.81)$. The 92 patients had a mean bilirubin level of $16.70 \pm 3.07 \mathrm{mg} / \mathrm{dL}$, with a mean of $16.42 \pm 3.53 \mathrm{mg} / \mathrm{dL}$ in the control group and $17.00 \pm$ $2.49 \mathrm{mg} / \mathrm{dL}$ in the probiotic group $(\mathrm{P}=0.37)$. The duration of hospitalization averaged $3.34 \pm 0.70$ days overall, with an average of $3.55 \pm 0.74$ days for the control group and $3.13 \pm 0.70$ days for the probiotic group. The probiotic group had a significantly lower hospitalization stay in comparison to the control group $(\mathrm{P}=0.004)$.

Conclusions: Our findings suggest that probiotics may be beneficial as an adjunct treatment for infants with hyperbilirubinemia by reducing the duration of hospitalization.
\end{abstract}

Keywords: Probiotics, Hyperbilirubinemia, Phototherapy, Hospitalization Duration

\section{Background}

Approximately $60 \%$ of term and $80 \%$ of premature infants are hospitalized for hyperbilirubinemia in the first week of life. Hyperbilirubinemia is the most common cause of hospitalization in infancy. Physiological icterus is a common cause of infantile hyperbilirubinemia which is diagnosed by ruling out other important etiologies such as hemolysis, infections, and metabolic disorders (1-3). Hyperbilirubinemia is the most common cause of readmission in early infancy $(4,5)$. In $2 \%$ of mature infants, bilirubin levels can reach more than $20 \mathrm{mg} / \mathrm{dL}$ which requires therapeutic action and may result in complications such as kernicterus and neurological damage (6).

The aim of managing hyperbilirubinemia is to pre- vent neurological damage. The most prevalent therapeutic method for managing infantile icterus and preventing its complications is phototherapy, which has been applied for decades as a safe method (7). However, higher levels of bilirubin may require a blood transfusion.

Previous studies have suggested medications such as metalloporphyrins, phenobarbital, clofibrate, and IVIG for management of hyperbilirubinemia (8-12). Active charcoal, agar, and cholestyramine are also used as adjuvants in decreasing bilirubin levels (13). Probiotics are microorganisms which can decrease the transit time of materials in the intestines (14). A few studies assessing the effect of probiotics on decreasing bilirubin levels have reported decreases in the required length of phototherapy (15-17). 


\section{Objectives}

This study aims to assess the adjunctive effect of probiotics on decreasing hospitalization time in order to address the related issues of the high frequency of infants hospitalized with hyperbilirubinemia and the high costs of treatment.

\section{Methods}

This randomized, controlled clinical trial was approved by the ethics committee of Baqiyatallah University of Medical Sciences and registered with the Iranian registry of clinical trials) Reference Number: IRCT2015021817413N11). Figure 1 shows a flowchart of the trial. Patients with hyperbilirubinemia who were admitted to the Neonatal Intensive Care Unit of Baqiyatallah Hospital from March to June 2014 were enrolled in the study. A written informed consent form was obtained from all of the guardians.

Infants with a gestational age of more than 35 weeks, birth weight of more than 2500 grams, bilirubin level of more than $15 \mathrm{mg} / \mathrm{dL}$, and direct bilirubin level of less than $1.5 \mathrm{mg} / \mathrm{dL}$ were included in the present study. Infants who were less than two days of age, were ill or septic, had a positive Coombs test, were undergoing blood transfusion or IVIG, were receiving phenobarbital therapy, required serum therapy, or whose parents were not willing for their children to participate in the experiment were excluded from the study. The patients who met the inclusion criteria were randomly assigned to two groups (control and probiotic) using a random-number tabulation. Serum therapy and taking phenobarbital, bilinaster, or manna was prohibited during the study.

The probiotic group was treated with half of a capsule of Prokid probiotic(Bifidobacterium lactis, Lactobacillus acidophilus, Bifidobacterium bifidum, and Lactobacillus rhamnosus). The control group used a placebo which was half of a capsule filled with a probiotic-free formula the same color as the Prokid probiotic. The probiotic and placebo capsules were prescribed once a day before breastfeeding. Neither the parents nor the nurse were informed whether the administered drug was a placebo or not.

The patients' bilirubin levels were measured using serum samples prior to admission and after treatment. All of the patients with bilirubin levels higher than $18 \mathrm{mg} / \mathrm{dL}$ underwent intensive phototherapy. Those with bilirubin levels between $14 \mathrm{mg} / \mathrm{dL}$ and $18 \mathrm{mg} / \mathrm{dL}$ underwent 8-lamp phototherapy. Those with bilirubin levels less than 14 $\mathrm{mg} / \mathrm{dL}$ were treated with 4-lamp phototherapy. Infants with bilirubin levels less than $10 \mathrm{mg} / \mathrm{dl}$ during the first week and less than $11 \mathrm{mg} / \mathrm{dl}$ after the second week were discharged. The duration of the phototherapy, the blood groups of mothers and infants, and the patients' bilirubin levels before and after phototherapy, direct Coombs test results, and levels of hemoglobin, G6PD, and reticulocytes were recorded.

Data were analyzed using SPSS software version 20 (SPSS Inc., Chicago, IL) for Microsoft Windows. The normal distributed variables (approved by a 1-sample KolmogorovSmirnov test) were compared using an independent sample t test between the groups. A Mann-Whitney U test was used to compare between the groups for variables that were not of a normal distribution. The chi-square test was used to compare categorical variables in the two groups and the Fisher test was used for all other conditions. A Pvalue of less than 0.05 was considered to be statistically significant.

\section{Results}

Data from 92 patients with a mean age of $5.25 \pm 2.35$ days underwent analysis. Table 1 summarizes the demographic and laboratory characteristics of the patients.

The distribution of birth weight between the two groups is summarized in Table 2. Most of the infants (52.2\%) weighed between 3000 and 3500 grams. There was no significant difference between the two groups for distribution of birth weight $(\mathrm{P}=0.18)$.

Most of the infants in both the probiotic (74\%) and control (79\%) groups were born by normal vaginal delivery. Eighty-five of the infants (92.4\%) were being breastfed and 7 of the infants $(7.6 \% ; 2$ in the probiotic group and 5 in the control group) received both breast milk and formula. There was no significant difference between the two groups with respect to the type of nutrition $(P=0.43)$.

On the first day of the study (before intervention), the 92 infants had a mean bilirubin level of $16.70 \pm 3.07 \mathrm{mg} / \mathrm{dL}$, with a mean of $16.46 \pm 2.33 \mathrm{mg} / \mathrm{dL}$ in the control group and $16.95 \pm 2.67 \mathrm{mg} / \mathrm{dl}$ in the probiotic group $(\mathrm{P}=0.35)$. Table 3 shows the mean bilirubin level trend in the patients before and after intervention. The day after intervention, the probiotic group had a significantly lower bilirubin level ( $P$ $=0.001)$. The mean bilirubin level decrease was $4.80 \pm 1.76$ in the probiotic group and $2.76 \pm 1.29$ in the control group the day after intervention $(\mathrm{P}<0.001)$. Most of the infants $(84.7 \%)$ in the probiotic group were discharged two days after intervention, but 32 of the infants $(69.5 \%)$ in the control group were still under treatment on the third day. At the time of discharge, infants had a mean bilirubin level of 9.72 $\pm 0.96 \mathrm{mg} / \mathrm{dL}$ in the probiotic group and $9.38 \pm 0.71 \mathrm{mg} / \mathrm{dL}$ in the control group $(\mathrm{P}=0.053)$.

The average duration of hospitalization was $3.34 \pm 0.70$ days overall, with an average of $3.55 \pm 0.74$ days for the con- 


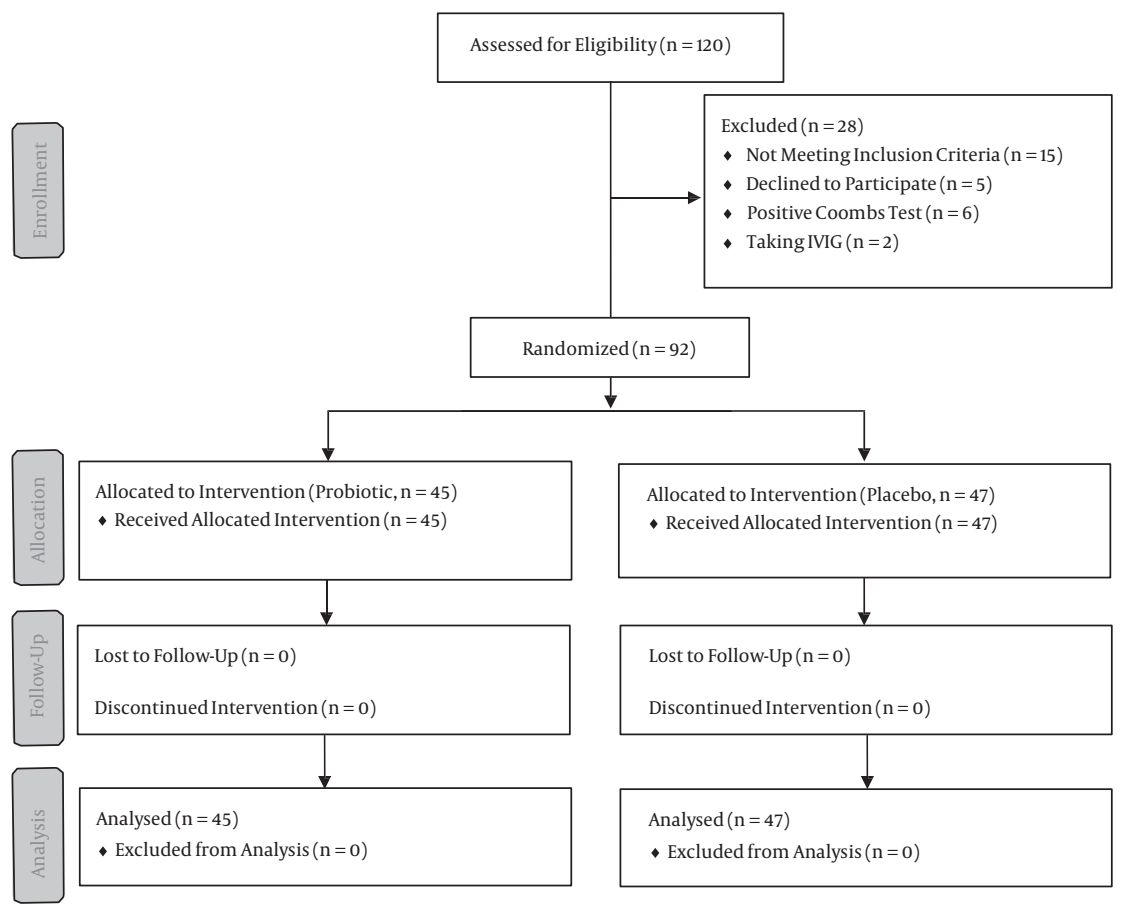

Figure 1. Study Flowchart

Table 1. Demographic and Laboratory Characteristics of Patients

\begin{tabular}{|c|c|c|c|}
\hline Variable & $\operatorname{Probiotic}(n=45)$ & Control $(n=47)$ & P Value \\
\hline Mean age, $d$ & $5.31 \pm 2.19$ & $5.19 \pm 2.51$ & 0.81 \\
\hline Male, No. (\%) & $17(37.7)$ & $23(48.9)$ & 0.2 \\
\hline Severe G6PD deficiency, No. (\%) & $2(4.4)$ & 1 & 0.61 \\
\hline Mean reticulocyte count & $1.77 \pm 1.96$ & $1.42 \pm 1.56$ & 0.34 \\
\hline Mean hemoglobin level, mg/dL & $16.29 \pm 1.31$ & $16.98 \pm 1.70$ & 0.03 \\
\hline
\end{tabular}

Table 2. Distribution of Birth Weight Between the Two Groups ${ }^{\mathrm{a}}$

\begin{tabular}{|c|c|c|c|c|c|}
\hline \multirow[t]{2}{*}{ Groups } & \multicolumn{3}{|c|}{ Birth Weight (Grams) } & \multirow[t]{2}{*}{ Total } & \multirow[t]{2}{*}{ PValue } \\
\hline & $2500-3000$ & $3000-3500$ & $>3500$ & & \\
\hline Control & $15(16.3)$ & $29(31.5)$ & $3(3.3)$ & $47(51.1)$ & \multirow{3}{*}{0.18} \\
\hline Probiotic & $14(15.2)$ & $19(20.7)$ & $12(13)$ & $45(48.9)$ & \\
\hline Total & $29(31.5)$ & $48(52.2)$ & $15(16.3)$ & $92(100)$ & \\
\hline
\end{tabular}

${ }^{\mathrm{a}}$ Values are expressed as No. (\%).

trol group and $3.13 \pm 0.70$ days for the probiotic group (Figure 2). The probiotic group had a significantly lower hospitalization stay in comparison to the control group $(\mathrm{P}<$ 0.001 , [CI $=95 \%,-1.31$ to -0.64$])$. Female patients had on average a significantly lower hospitalization duration in comparison to male patients $(\mathrm{P}=0.005)$. No significant association was found between birth weight or age and the length of hospitalization duration $(\mathrm{P}>0.05)$ (Table 4$)$.

\section{Discussion}

In the present study we found that the adjuvant prescription of probiotics with phototherapy reduces the hospitalization duration in infants with hyperbilirubinemia. Only one similar study has been conducted with very low birth weight infants and no studies have yet been conducted with term infants (15). 
Table 3. Mean Bilirubin Level Trend in Patients

\begin{tabular}{|c|c|c|c|c|c|}
\hline \multirow[t]{2}{*}{ Day } & \multicolumn{2}{|c|}{ Probiotic } & \multicolumn{2}{|c|}{ Control } & \multirow[t]{2}{*}{ PValue } \\
\hline & Mean \pm SD & $\mathbf{n}$ & Mean \pm SD & n & \\
\hline $\mathbf{1}$ & $16.95 \pm 2.67$ & 45 & $16.46 \pm 2.33$ & 47 & 0.35 \\
\hline 2 & $12.12 \pm 2.16$ & 45 & $13.71 \pm 2.13$ & 47 & 0.001 \\
\hline 3 & $10.14 \pm 1.17$ & 38 & $10.91 \pm 1.88$ & 47 & 0.026 \\
\hline 4 & $10.10 \pm 1.11$ & 7 & $10.15 \pm 1.49$ & 32 & 0.930 \\
\hline 5 & 9.8 & 1 & $10.29 \pm 1.41$ & 10 & 0.749 \\
\hline 6 & - & 0 & $10.76 \pm 1.26$ & 3 & - \\
\hline 7 & - & 0 & 10.6 & 1 & - \\
\hline
\end{tabular}

Table 4. Relation of Birth Weight and Age With Number of Days Hospitalized

\begin{tabular}{llcc}
\hline & & Age & Birth Weight \\
\hline \multirow{2}{*}{ Days } & Spearman's rank correlation & 0.070 & -0.059 \\
& P Value & 0.507 & 9.577 \\
\hline
\end{tabular}

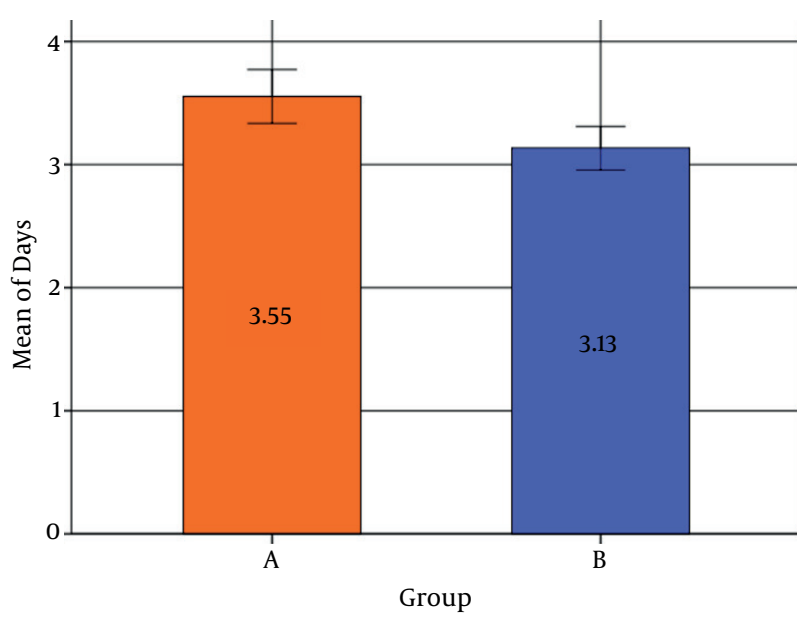

Figure 2. Mean of Hospitalization Days in the Two Study Groups

The aim of hyperbilirubinemia management is to prevent the indirect bilirubin levels from reaching the point at which neurotoxicity may occur. Possible complications of hyperbilirubinemia include deafness and kernicterus. Phototherapy is the treatment of choice for infant hyperbilirubinemia, and was administered equally for the infants in both groups in the present study (18). However, long-term phototherapy is associated with complications such as erythematous rashes, diarrhea, and hyperthermia.

The social and economic burdens of hospitalization have led to the application of nursery services at home such as at-home phototherapy. Hospitalization in a government hospital for a mature, healthy infant costs three times more than at-home phototherapy, and the same treatment is six times more expensive in non-government hospitals. Finding a way to decrease the hospitalization duration has several benefits including lower expenses and more emotional contact between mother and child (19-21). Thus, finding a way to reduce the phototherapy period is necessary in both the economic and medical aspects.

The prescription of a variety of drugs such as clofibrate and phenobarbital has been proposed for reducing hospitalization duration (18). However, phenobarbital has been shown to have no significant clinical effect on treating hyperbilirubinemia except the dominant type of CriglerNajjar syndrome (10). Active charcoal, agar, and cholestyramine are non-absorbable oral agents which decrease enteric absorption of bilirubin and its serum level by reducing the enterohepatic cycle (13). Caglayan et al. demonstrated that a combination of agar and phototherapy was more effective than phototherapy alone (22).

An increase in bowel transit, which was induced by probiotics in our study, is one of the potential ways of decreasing treatment duration of physiological hyperbilirubinemia, although laxatives were shown to be not effective in managing infant hyperbilirubinemia in another study (10).

The purpose of probiotics is to increase the number of beneficial bacteria in the bowels. No adverse effects from the administered probiotics were found in the present study. Recently, probiotics have been shown to be useful for treating gastroenteritis by slowing bacterial growth (23). They can decrease the passing time of materials in the bowels, regulate smooth muscle contraction, and increase the reproduction of enterocytes (14).

Demirel et al. evaluated the effect of a Saccharomyces boulardii probiotic supplement on the course of hyper- 
bilirubinemia and the duration of treatment in 179 very low birth weight infants in a clinical trial. They reported that the duration of phototherapy was significantly lower in the probiotic group in comparison to the control group which is in accordance with the present study. The incidence of feeding intolerance was also lower in their study group (15).

The present study has some limitations. No long-term follow-up regarding the possible side effects of the probiotics was performed for the patients. In addition, the frequency of defecation in both groups is another factor that should be considered in future studies.

In conclusion, our findings suggest that probiotics may be beneficial as an adjunct treatment for infants with hyperbilirubinemia by reducing the duration of hospitalization. Further in-depth studies are necessary to establish the effect of probiotics on the course of hyperbilirubinemia.

\section{Footnotes}

Authors' Contribution: Mohammad Torkaman designed the study; Fatemeh Mottaghizadeh helped collect data and draft the manuscript; Mohammad Hossein Khosravi helped collect and analyze data and also helped draft the manuscript; Bita Najafian helped design the study and collect data; Susan Amirsalari did critical editing and revision on the manuscript; Shahla Afsharpaiman helped with data collection.

Ethical Consideration: The present study was approved by the ethics committee of Baqiyatallah University of Medical Sciences. All of the terms of the Declaration of Helsinki were followed. The guardians were asked to sign an informed consent form prior to the participation of their children in the study.

Financial Disclosure: The authors declare no conflicts of interest or financial issues for the present study.

\section{References}

1. Halamek LPSD. Neonatal jaundice and liver disease. 9 ed. Philadelphia: Mosby: St. Louis; 2011. pp. 1309-50.

2. Facchini FP, Mezzacappa MA, Rosa IR, Mezzacappa Filho F, AranhaNetto A, Marba ST. Follow-up of neonatal jaundice in term and late premature newborns. J Pediatr (Rio J). 2007;83(4):313-22. doi: 10.2223/JPED.1676. [PubMed: 17676235].

3. Boskabadi H, Maamouri G, Mafinejad S. The Effect of Traditional Remedies (Camel's Thorn, Flixweed and Sugar Water) on Idiopathic Neonatal Jaundice. Iran J Pediatr. 2011;21(3):325-30. [PubMed: 23056809].

4. Maisels MJ, Kring E. Length of stay, jaundice, and hospital readmission. Pediatrics. 1998;101(6):995-8. [PubMed: 9606225].
5. Sarici SU, Yurdakok M, Serdar MA. An early (sixth-hour) serum bilirubin measurement is useful in predicting the development of significant hyperbilirubinemia and severe ABO hemolytic disease in a selective high-risk population of newborns with $\mathrm{ABO}$ incompatibility. Pediatr. 2002;109(4):53.

6. Maisels JM. Jundice. 6 ed. Philadelphia: Lippincott Williams \& Wilkins; 2005. pp. 825-33.

7. Wrong RJGH, Sibley DG. Therapy of unconjugated hyperbilirubinemia. 8 ed. Philadelphia: Mosby; 2006. pp. 1440-5.

8. Bourget P, Broise I, Quinquis-Desmaris V, Gabilan JC. [Pharmacokinetics of clofibrate in jaundiced newborn infants at term]. Arch Pediatr. 1995;2(8):722-8. [PubMed: 7550835].

9. Gabilan J, Benattar C, Lindenbaum A. Clofibrate treatment of neonatal jaundice. Pediatr. 1991;88(6):1292-4.

10. Dennery PA. Pharmacological interventions for the treatment of neonatal jaundice. Semin Neonatol. 2002;7(2):111-9. [PubMed: 12208095].

11. Sharafi R, Mortazavi Z, Sharafi S, Parashkouh RM. The Effect of Clofibrate on Decreasing Serum Bilirubin in Healthy Term Neonates under Home Phototherapy. Iran J Pediatr. 2010;20(1):48-52. [PubMed: 23056681].

12. Ebrahimi S, Ashkani-Esfahani S, Poormahmudi A. Investigating the efficacy of Zizyphus jujuba on neonatal jaundice. Iran J Pediatr. 2011;21(3):320-4.

13. Suresh G, Martin C, Soll R. Treatment of unconjugated hyperbilirubinemia in neonates. Oxford; 2003.

14. Husebye E, Hellstrom PM, Sundler F, Chen J, Midtvedt T. Influence of microbial species on small intestinal myoelectric activity and transit in germ-free rats. Am J Physiol Gastrointest Liver Physiol. 2001;280(3):368-80. [PubMed: 11171619].

15. Demirel G, Celik IH, Erdeve O, Dilmen U. Impact of probiotics on the course of indirect hyperbilirubinemia and phototherapy duration in very low birth weight infants. J Matern Fetal Neonatal Med. 2013;26(2):215-8. doi: 10.3109/14767058.2012.725115. [PubMed: 22937831].

16. Serce O, Gursoy T, Ovali F, Karatekin G. Effects of Saccharomyces boulardii on neonatal hyperbilirubinemia: a randomized controlled trial. Am J Perinatol. 2015;30(2):137-42. doi: 10.1055/s-0034-1376390. [PubMed: 24915562].

17. Armanian AM, Barekatain B, Hoseinzadeh M, Salehimehr N. Prebiotics for the management of hyperbilirubinemia in preterm neonates. J Matern Fetal Neonatal Med. 2016;29(18):3009-13. doi: 10.3109/14767058.2015.1113520. [PubMed: 26513278].

18. Hansen TW. Recent advances in the pharmacotherapy for hyperbilirubinaemia in the neonate. Expert Opin Pharmacother. 2003;4(11):1939-48. doi: 10.1517/14656566.4.11.1939. [PubMed: 14596647].

19. Rogerson AG, Grossman ER, Gruber HS, Boynton RC, Cuthbertson JG. 14 years of experience with home phototherapy. Clin Pediatr (Phila). 1986;25(6):296-9. [PubMed:3698452].

20. Eggert LD, Pollary RA, Folland DS, Jung AL. Home phototherapy treatment of neonatal jaundice. Pediatrics. 1985;76(4):579-84. [PubMed: 4047802].

21. Kappas A, Drummond GS, Valaes T. A single dose of Sn-mesoporphyrin prevents development of severe hyperbilirubinemia in glucose6-phosphate dehydrogenase-deficient newborns. Pediatrics. 2001;108(1):25-30. [PubMed: 11433050].

22. Caglayan S, Candemir H, Aksit S, Kansoy S, Asik S, Yaprak I. Superiority of oral agar and phototherapy combination in the treatment of neonatal hyperbilirubinemia. Pediatrics. 1993;92(1):86-9. [PubMed: 8516090].

23. Guarner F, Malagelada JR. Gut flora in health and disease. Lancet. 2003;361(9356):512-9. doi: 10.1016/S0140-6736(03)12489-0. [PubMed: 12583961] 